Session 1526

\title{
Incorporating Electric Drives into the Electrical Machines Course: A Systems Level Approach
}

\author{
Steven M. Hietpas and Michael E. Ropp \\ Department of Electrical Engineering, \\ South Dakota State University, SD 57007
}

\begin{abstract}
Over the last 35 years, the advent of power electronics has extensively impacted almost every aspect of Electromechanical Energy Conversion (EMEC). The effective integration of power electronics, electric drives, and system issues into the EMEC curriculum demands a significant redesign of both the course and laboratory exercises. One such redesign, currently being supported under the Adaptation and Implementation track of the NSF's CCLI program, is the subject of this paper. An existing undergraduate "electric machines" course has been converted into an "EMEC systems" course in which power generation, power processing, and end-use equipment are integrated. A "just-in-time" strategy has been adapted and implemented into the EMEC course. Of particular interest is the need to provide students with end-to-end instruction on the analysis and design steps followed in the development of an electric drive system.
\end{abstract}

\section{Introduction}

Power electronic devices have enabled unprecedented control over and flexibility of EMEC, and because of their advantages such devices have become extremely common in practice and continue to become more prevalent ${ }^{1}$. Today, electric machines are frequently only one component in an EMEC system (frequently referred to as a "drive"). Clearly, the "traditional" education in EMEC, which considers electric machines in isolation and barely mentions power electronics, no longer adequately prepares undergraduate students for a career in power engineering.

The effective integration of power electronics, electric drives, and system issues into the EMEC curriculum demands a significant redesign of both the course and laboratory exercises. Such a redesign has been undertaken at South Dakota State University (SDSU) and supported by a grant from NSF under the A\&I track of CCLI' ${ }^{2}$, which began in January of 2000 and is scheduled for completion in December of 2001. This paper discusses the EMEC course redesign, including the approach adopted, logistical challenges, and results to date. 
The paper is divided into six sections. An overview of the redesign of the EMEC course is provided in section II. Section III discusses the proposed EMEC course outline for phase 1 of the 2 -year project. It begins with a statement of the primary objective of the course and follows with reasons for the selection of subject matter related to the teaching of electric drives. Section IV builds on section III by providing a thorough discourse on details of topics covered within the course, reasons for supplementing material from the selected textbook and the laboratory exercises implemented to meet the primary objectives of the 2-year project. It is noted in section IV that not all objectives were met in the first phase of this project, hence, section V offers solutions to achieving this objective and a plan of suggested changes to the EMEC course outline proposed in section III. The paper concludes in section VI with a summary of the paper and concluding remarks.

\section{EMEC Course Redesign Project Overview}

The new EMEC course and associated laboratory centers around a Power Workstation Bench (PWB) at which students may experiment with power electronics and electric machines, and also with certain distributed generation technologies ${ }^{3}$. The electric machine course/laboratory (EE430/EE431) has been converted into an "EMEC systems" course/laboratory in which power generation, power processing, and end-use equipment are integrated. A "just-in-time" strategy that has successfully been developed at the University of Minnesota for their "First Course on Electric Drives" ${ }^{4}$ is being adapted and implemented into the EMEC courses. The project was divided into essentially two phases, the first involving the restructuring of the course material and associated lab exercises. The second phase involves the design, construction and testing of the new lab exercises.

During the summer of 2000 the first author developed a complete set of on-line notes ${ }^{5}$ based on the recently published book on electric drives by Ned Mohan of the University of Minnesota ${ }^{6}$. In the course of the development of the notes, numerous simulations and animations were constructed to best incorporate the teaching of electric drives with machines ${ }^{7}$.

The greatest challenge throughout this development was the selection of course content that would allow optimum coverage of each of the three areas (generation, power processing, and end-use equipment), while keeping in mind the necessary development of complementary laboratory exercises. Decisions regarding which electric drive subjects were taught, and how much time was allocated to each subject, were governed by a variety of logistical factors, such as laboratory equipment and resources, research assistant knowledge of material, and the time frame for this project. The outcome of this development is discussed in the next three sections. 


\section{Proposed EMEC Course Outline (Phase 1)}

The primary objective in revising the course material is to provide the student with end-to-end instruction on the analysis and design steps generally followed in the development of an electric drive system. An electric drive system includes generation, power electronic drive or power processing unit (PPU), motor, and load components. By end-to-end instruction we mean teach the student to design an electric drive system, with appropriate understanding of the role that generation and end-use (motor plus load) affects the design of the PPU.

This objective correlates well with Accreditation Board for Engineering and Technology (ABET), Accrediting Engineering Programs, criterion 3 (Program Outcomes and Assessment), item (c), which states "Engineering programs must demonstrate that their graduates have an ability to design a system, component, or process to meet desired needs" 8 . While it is important to be able to model the source (generation) and load with sufficient detail, we emphasized the modeling, analysis, and design of the power electronic drive and motor in phase 1 . The second phase of this project will address in greater detail the generation side of the electric drive system, with some additional attention given to loading effects.

The end-to-end instruction of the electric drive system objective was the impetus behind the selection of course subject material, while taking into account resources and time constraints of the first phase of the project. Mohan's book on electric drives ${ }^{6}$ was adopted for the fall EMEC course. Table 1 summarizes the book's contents.

For phase 1 of this project we limited the course and laboratory development to DC and 3-phase AC Induction Motors and their respective PPUs.

The course was organized following a "just-in-time approach"4 philosophy in which concepts and techniques are taught as they are needed. Another way to think of this philosophy is that students are directed to approach a problem using existing skills and knowledge, and they proceed until an aspect is reached that requires new skills. The new information is taught at that time. The "just-in-time approach" thus parallels the actual design procedure, as opposed to the traditional approach, which attempts to establish a complete knowledge base before pursuing the problem.

Keeping in mind the end-to-end objective, the fall EMEC course was divided into essentially three parts and taught in the sequence shown in Table 2. 
Table 1: Contents of Electric Drives - An Integrative Approach ${ }^{6}$

\begin{tabular}{|cc|}
\hline $\begin{array}{c}\text { Chapter } \\
1\end{array}$ & Topic \\
2 & Introduction to Electric Drive Systems \\
3 & Understanding Mechanical System Requirements for Electric Drives \\
4 & Review of Basic Electric Circuits \\
5 & Basic Understanding of Switch-Mode Power Electronic Converters in Electric Drives \\
6 & Magnetic Circuits \\
7 & Basic Principles of Electro-mechanical Energy Conversion \\
8 & DC-Motor Drives and Electronically-Commutated Motor Drives \\
9 & Designing Feedback Controllers for Motor Drives \\
10 & Introduction to AC Machines and Space Vectors \\
11 & Sinusoidal Permanent Magnet AC (Brushless DC) Drives, LCI-Synchronous Motor \\
12 & Drives, and Synchronous Generators \\
13 & Induction-Motors: Balanced, Sinusoidal Steady State Operation \\
14 & Induction-Motor Drives: Speed Control \\
15 & Vector Control of Induction-Motor Drives: A Qualitative Examination \\
16 & Reluctance Drives: Stepper-Motor and Switched-Reluctance Drives \\
17 & Energy Efficiency of Electric Drives and Inverter-Motor Interactions \\
& Powering Electric Drives: Power Quality Issues \\
\hline
\end{tabular}

Table 2: Proposed EMEC course outline (Phase 1)

\begin{tabular}{|clc|}
\hline Part & \multicolumn{1}{c}{ Primary Topics } & Chapters from Mohan ${ }^{6}$ \\
$\mathbf{1}$ & $\begin{array}{l}\text { Introduction of the Electric Drives Systems and } \\
\text { Review Material Associated with Electric Drives }\end{array}$ & $1-3,5$ and 6 \\
$\mathbf{2}$ & DC Motors, Power Electronic Converters and Drives & 7 and 4 \\
$\mathbf{3}$ & AC Induction Motors and Power Electronic Drives & 9 and 11-12 \\
\hline
\end{tabular}

Chapter 8 covers the design of feedback controllers and was not covered due to time constraints. Chapter 13 covers the Vector Control of Induction-Motor Drives from a qualitative examination. This subject is specific to the area of induction motor position control, a subject that is beyond the scope of this course. 


\section{EMEC Course Development and Associated Laboratory Exercises}

The transformation of a machines course into an electric drive systems course is not achieved without some degree of pain and suffering. It is the authors' desire that the following discussion will aid others in the revision of their machines courses with minimal discomfort. Following is a summary of topics selected for the course, their degree of coverage, supplemental materials/methods used outside of the material provided in the course textbook, and associated laboratory exercises.

\section{$\underline{\text { Part } 1}$}

Part 1 (Table 2) of the EMEC course focused on introductory issues, such as answering the question "What is an Electric Drive?", and its applications, modeling of mechanical systems and the need for 4-quadrant electrical drives, review of three-phase electric and simple magnetic circuits, and the basic principles of electro-mechanical energy conversion. The coverage of this material required a total of 13 lectures. During that time the students were able to conduct 4 laboratory exercises. The development of this material was fairly standard in nature requiring little in the way of animated graphics for illustrating difficult concepts. Perhaps the aspect that seemed to capture student attention the most was the use of PSpice ${ }^{\circledR}$ to model the analogous representation of mechanical systems.

The first several lectures were concerned with an overview of electric drive systems and to complement this material the first laboratory exercise introduces the students to a small scale Supervisory Control and Data Acquisition (SCADA) system ${ }^{9}$. The SCADA system is comprised of a motor/generator set with Volts/Hz 3-phase motor drive, load bank, signal conditioning unit, and a PC with a LabVIEW ${ }^{\circledR}$ interface. All functions of the system are controllable by the student via LabVIEW $^{\circledR}$ and the PC, allowing system measurements of current, voltage, power and motor speed. The system also allows the student to program a motor speed profile as well as a peakload setting for closed-loop control. Under closed-loop control a random load-shedding algorithm is initiated whenever the load demand exceeds the peak-load setting. Though the primary objective of this SCADA exercise was to expose the students to a realistic electric drive system, the students are guided through a short procedure for programming the system using LabVIEW's ${ }^{\circledR}$ virtual instrument (object oriented) software platform. To reacquaint students with power circuitry (their first exposure may well have been 2 years prior), the second laboratory exercise deals with the analysis and measurement techniques for 3-phase systems. This laboratory exercise also introduces the student to a variety of laboratory equipment and safety precautions they will use throughout the semester. To complement the material associated with magnetics and in preparation for the modeling of a 3-phase induction motor, the third exercise requires the students to gather appropriate test data on a $2 \mathrm{kVA}$ transformer, develop its equivalent circuit and conduct a performance analysis. Finally, accompanying the introduction to electromechanical energy conversion, the students are required to construct a fractional hp DC motor from materials commonly available at a hardware store (we provide the enamel coated 
wire). The students are challenged to follow a set of step-by-step instructions in the construction of the motor. Each group is evaluated based on the maximum rotational speed their motor achieves. This lab exercise has been extremely popular for the students and proved to be an excellent introduction to the detailed discussion on dc motors and drives, covered in part 2. Proper treatment and complementary yet practical exercises for the material in part 1 are crucial to the success of parts 2 and 3. However, it is very easy to allocate too much time to part 1 and not allow enough time to achieve the primary goal of providing end-to-end analysis and design for two electric drive systems.

\section{$\underline{\text { Part } 2}$}

Following the just-in-time philosophy, part 2 is comprised of all DC-related material. This includes the modeling and analysis of a DC motor followed by the development of DC power electronic fundamentals and the 2- and 4-quadrant DC motor PPU. Part 2 concludes with the treatment of our first complete "electric drive" comprised of a DC power electric converter connected to a permanent magnet dc motor. The coverage of this material required a total of 8 lectures. During that time the students were able to conduct 3 laboratory exercises. Some supplementary material on PPU ${ }^{10,11}$ was incorporated at this point to better facilitate laboratory exercises.

The development of DC-DC converter fundamentals in chapter 4 is approached from a systems level point of view, using current-to-voltage poles to describe the switching circuitry. These poles constitute building blocks of the converter. This approach conveniently leads into the concept of averaging and generalizes the basic function of the converter into a small signal to large signal amplifier. The control signal (small signal), in combination with a triangular waveform, produces the necessary pulse-width modulation (PWM) that converts the large input signal to a desired output voltage (large signal). From a systems and controls point of view (chapter 8), this is appropriate. However, in our experience, approaching the concept of the DC-DC converters from a volt-second balance ${ }^{12}$ approach proved beneficial, not only to student's understanding of the fundamentals of converters, but also in the development of complementary and practical laboratory DC-DC converter and DC motor drive exercises.

The first of the three DC-related laboratory exercises requires students to perform appropriate tests on the permanent magnet motor to aid in the construction of a circuit model. This circuit model was implemented in PSpice ${ }^{\circledR}$ and transient and steady state simulations for various loading conditions were performed and compared to data recorded in the lab. Manufacturer motorparameter data was substituted for experimental values and further comparisons and parameter evaluations were performed. The second DC-related exercise introduces the students to a buck DC-DC converter. As it is not practical for the students to design and construct the entire converter, they were tasked to design and fabricate the choke inductor according to a desired set of specifications. To expedite the design of the inductor, design software for iron powder cores from Micrometals Inc. ${ }^{13}$ was used. The laboratory exercise consisted of evaluating the choke 
inductor and converter performance. The third exercise upgraded the buck converter to a 2-quadrant PPU designed to operate the permanent magnet motor the students modeled in the first DC lab exercise. Performance was predicted through PSpice ${ }^{\circledR}$ simulation of the combined motor drive and DC motor, and then compared to actual performance data taken in the laboratory.

Initial feedback from students was positive in that most felt that they learned fundamentals of DC-DC converters and their applications in DC motor drives. Numerous students felt the laboratory exercises demanded too many results and believed they could be simplified without sacrificing the essential objectives.

\section{Part 3}

Part 3 is comprised of all AC-related material. This includes the modeling and analysis of an AC induction motor followed by the development of an $\mathrm{AC}$ volts/ $\mathrm{Hz} 3$-phase motor drive. Part 3 concludes with the treatment of our second complete "electric drive" comprised of an AC power electric converter connected to a 3-phase AC induction motor. The coverage of this material required a total of 14 lectures. During that time the students were able to conduct 2 laboratory exercises.

Chapter 9 of Mohan's book ${ }^{6}$ introduces the students to the concept of space vectors and the nature of the rotating (traveling) electromagnetic field within the gap of the three-phase induction motor. The mathematical development of the space vector and its use in understanding the rotating field was supplemented through numerous gif animations ${ }^{7}$. The animated $g$ if files were generated using Mathworks Matlab ${ }^{\circledR} \operatorname{code}^{14}$, MS Visio2000 ${ }^{\circledR}$ and Macromedia ${ }^{\circledR}$ Fireworks ${ }^{\circledR} 3$ software packages. These animations and Matlab ${ }^{\circledR}$ simulations proved very useful in helping the students grasp the relatively complicated development of the space vector concept and the equivalent circuit model and operation of the 3-phase induction motor. In order for the student to understand the basic understanding of a 3-phase induction motor speed drive, addressed in chapter 12 , a fairly complete circuit model and laboratory tests to obtain motor parameters are provided in chapter 11. The last subject covered in part 3 focused on the development of the Volts/Hz motor drive and its effect on the 3-phase motor torque vs. speed curve and starting performance characteristics.

The first laboratory exercise tasks students to produce an electric circuit model of a 3-phase 3-hp induction motor. The tests performed were modified versions from those provided in the course textbook and based on developments from Cathey's recently published book on electric machines ${ }^{14}$. Following standard blocked rotor and no-load tests, the electric circuit parameters were determined. The second laboratory exercise requires the students to construct the motor model in PSpice ${ }^{\circledR}$ and perform appropriate simulations to evaluate the accuracy of the parameters. A Volts/Hz motor drive was used in lab to make predetermined adjustments to both drive output voltage and frequency to obtain enough performance data to compare to simulations 
from PSpice ${ }^{\circledR}$. This exercise was not performed in its entirety due a variety of challenges (recall that introducing power electronics into the machines class is not accomplished without some degree of pain and suffering).

\section{Proposed EMEC Course Outline (Phase 2)}

As stated in section III, the primary objective in revising the course material is to provide the student with end-to-end instruction on the analysis and design steps generally followed in the development of an electric drive system. The results discussed in section IV show that it is possible to make further refinements and improvements to better attain this goal. Some of the topics not addressed in Phase 1 include generation and more detailed analysis of loading effects on the complete electric drive system. Following is an outline and discussion of a modified course outline, as well as new and modified exercises, that address these issues.

To address the issue of generation, we anticipate introducing the students to a photovoltaic (PV) array combined with a DC-DC converter system. This system can be used to illustrate many DCDC converter and DC motor concepts, as well as introducing basic concepts related to generators such as limits on available power, voltage and current. The PV array allows this to be done relatively safely, since its short-circuit current is limited. This subject can be introduced in part 2, where the topics are DC-related. To address the issue of different types of loads and their impact on the overall design and analysis process of electric drive systems, an exercise involving the coupling of an AC induction motor and electric drive to the operation of a hoist (constanttorque load) or a winder (constant-power load) may be implemented. With the addition of these two laboratory exercises, the total number of exercises stands at 11. Practically speaking, in a given semester, it is possible to offer at most 12 exercises. The $12^{\text {th }}$ exercise will be centered on the design and analysis of a 3-hp Volts/Hz AC induction motor drive.

\section{Conclusion}

We have presented an EMEC course outline that effectively incorporates generation, electric drives (PPU), and loading effects into the "traditional" machines course. A "just-in-time" strategy has been adapted and implemented into the EMEC course and the primary objective of providing students with "end-to-end" instruction on the analysis and design steps typically followed in the development of electric drive systems has been presented. A thorough discourse on details of topics covered within the course (recently taught in the Fall of 2000), reasons for supplementing material from the selected textbook and the laboratory exercises implemented to meet this primary objective were provided. Lastly, solutions for achieving the primary objective and suggested changes to the EMEC course outline were proposed for the second phase of this project. 


\section{Acknowledgements}

The authors express their appreciation to the National Science Foundation and the Curriculum and Laboratory Development Program, grant number DUE-9952517, for their support of this project. Additional gratitude is extended to the late Russell E. Christiansen, retired CEO of MidAmerican Energy and the Christiansen Family Foundation, to Xcel Energy Corporation (formerly Northern States Power Company), South Dakota State University alumni, and the SDSU Center for Power System Studies for their significant contributions.

\section{Bibliography}

1. B. Bose, et al, Power Electronics and Variable Frequency Drives, Technology and Applications, IEEE Press, (1997).

2. S. M. Hietpas and M. E. Ropp, "Improving Undergraduate Power Engineering Education: A System-Level Approach to Teaching Electromechanical Energy Conversion,” NSF-CCLI A\&I Grant, \# DUE-9952517, June 1999.

3. Kambhammettu Vijay, James Ziebarth, Michael Ropp, Steven Hietpas and Lewis Brown, "Proposal for New Energy Laboratory in the Crother's Engineering Hall Addition", South Dakota State University, Department of Electrical Engineering, Brookings, SD, Jan. 21, 2001.

4. NSF-Faculty Workshop on Teaching of Electric Drives, University of Minnesota, Department of Electrical Engineering, Minneapolis, June 19-21, 1997.

5. S. M. Hietpas, "Redesign of Energy Conversion -- EE430 -- using electromagnetic simulations and animations," Final Report, Governor's Technology Program, South Dakota, Oct. 23, 2000.

6. N. Mohan, Electric Drives - An Integrative Approach, University of Minnesota Printing Services, Minneapolis, MN, (2000).

7. S. M. Hietpas, "Using Multimedia Tools For Teaching Electric Drives," NSF Workshop on Multimedia Delivery of Modern Power Electronics Systems," University of Central Florida, School of Engineering and Computer Science, Orlando, Nov. 11-13, 2000.

8. URL: http://www.abet.org/downloads/2001-02_Engineering_Criteria.pdf; Accreditation Board for Engineering and Technology (ABET), "Criteria for Accrediting Engineering Programs, 2001-2002 Accreditation Cycle", page 1 .

9. T. Berge, J. Borman, and T. Rasmussen, "Small Scale Supervisory Control and Data Acquisition (SCADA) System." Final Design Review Report, Senior Design II, EE465, Electrical Engineering Department, South Dakota State University, May 1998.

10. N. Mohan, T. Undeland, and W. Robbins, Power Electronics: Converters, Applications, and Design, $2^{\text {nd }}$ edition, John Wiley \& Sons, New York, NY, (1995).

11. M Rashid, Power Electronics: Circuits, Devices, and Applications, $2^{\text {nd }}$ edition, Prentice Hall, Englewood Cliffs, NJ, (1993).

12. T. Wildi, Electrical machines, drives, and power systems, $4^{\text {th }}$ edition, Prentice Hall, Upper Saddle River, NJ, (2000).

13. URL: http://www.micrometals.com/software.html; Micrometals Inductor Design Software, Micrometals Inc., Anaheim, CA.

14. J. J. Cathey, Electricmachines - Analysis and Design Applying Matlab ${ }^{\circledR}$, McGraw Hill, New York, NY, (2001). 


\section{STEVEN M. HIETPAS}

Steven Hietpas received the B.S. degree in Electrical Engineering from Montana State University in 1984. In 1991 and 1994 he received his M.S. and Ph.D. degrees from the same university. From 1984 to 1989 he worked for the Space Energy Group at Space Systems Division of General Dynamics in San Diego. There he worked in research and development of power processing/power electronics for the Shuttle Centaur program and the International Space Station program. He has been on faculty at South Dakota State University since 1994 and currently holds the position of Associate Professor and serves as the Coordinator for the Center for Power System Studies. His research interests include power electronics, electric drives, FACTS devices, and control systems.

MICHAEL E. ROPP

Dr. Ropp received the B.S. degree in Music from the University of Nebraska in 1993, and the M.S. and Ph.D. degrees in Electrical Engineering from the Georgia Institute of Technology in 1996 and 1998, respectively. He joined the Electrical Engineering Department at South Dakota State University in 1999 as an Assistant Professor. His research interests include renewable energy, electric transportation, and power electronics. 